\title{
A juventude e a(s) política(s): Desinstitucionalização e individualização
}

Young People and Politics: Disinstitutionalization and Individualization

La jeunesse et la(les) politique(s): desinstitutionnalisation et individualisation

\section{Nuno Miguel Augusto}

\section{CpenEdition}

\section{Journals}

Edição electrónica

URL: http://journals.openedition.org/rccs/658

DOI: $10.4000 /$ rccs. 658

ISSN: 2182-7435

Editora

Centro de Estudos Sociais da Universidade de Coimbra

Edição impressa

Data de publição: 1 Junho 2008

Paginação: 155-177

ISSN: 0254-1106

Refêrencia eletrónica

Nuno Miguel Augusto, «A juventude e a(s) política(s): Desinstitucionalização e individualização », Revista Crítica de Ciências Sociais [Online], 81 | 2008, colocado online no dia 01 outubro 2012, criado a 02 maio 2019. URL : http://journals.openedition.org/rccs/658 ; DOI : 10.4000/rccs.658 


\title{
NUNO MIGUEL AUGUSTO
}

\section{A juventude e a(s) política(s): Desinstitucionalização e individualização}

\begin{abstract}
A relação que os jovens mantêm com o sistema democrático e, muito particularmente, com os modelos convencionais de participação política tem constituído uma das preocupações fundamentais associadas ao funcionamento e sustentabilidade intergeracional das democracias ocidentais. Frequentemente, a responsabilidade acaba por cair sobre os ombros da própria juventude, tendo por base critérios como a idade, a "irresponsabilidade" ou a "imaturidade", uma explicação que tem vindo a ser repensada nos últimos anos, como resultado quer da crise de representação, quer das mudanças na condição juvenil. Seguindo uma linha de análise assente numa mútua responsabilização (dos jovens e das instituições políticas) procuramos avaliar em que medida a juventude portuguesa reflecte estas tendências e quais os principais motivos para o aparente desencantamento políticos dos jovens. Para tal, cruzámos três dimensões fundamentais - a mobilização política, a confiança e a participação - com o intuito de verificar em que medida as hipóteses teóricas mais recentes poderão contribuir para uma explicação sociologicamente mais sustentada da (escassa) relação que os jovens mantêm com a política e com o sistema democrático.
\end{abstract}

\section{Introdução}

A relação entre juventude e política tem obedecido a uma diversidade de interpretações, que oscilam frequentemente entre uma visão "romântica" e uma visão pejorativa, dependendo do modo como os jovens reagem a diferentes contextos socio-históricos. Se, nuns casos, os jovens surgem como uma geração questionadora dos valores políticos erigidos pelas gerações anteriores, noutros, surgem como uma geração "endemicamente apolítica", desinteressada e fracamente envolvida nos processos democráticos.

Os últimos anos têm sido marcados por uma preocupação comum à maioria das democracias ocidentais - o afastamento dos jovens dos processos democráticos convencionais. Essa preocupação consta, inclusivamente, do Livro Branco para a Juventude da Comissão Europeia, onde se afirma que "os jovens investem, menos do que no passado nas estruturas tradicionais de acção política" (2001: 10). Mas até que ponto essa realidade afecta países como Portugal, que ainda há pouco tempo conheceu 
as primeiras gerações democráticas? Será que os jovens portugueses se afastam mais da política do que os seus pais? Por que motivos? E até que ponto esse afastamento significa um apoliticismo? Para respondermos a estas questões, precisamos, primeiro que tudo, de adoptar uma visão mais alargada e teoricamente mais sustentada da relação entre jovens e política.

A responsabilidade por este alheamento político acaba por recair essencialmente sobre as características psicossociais da juventude, entendida comummente como "fútil, indigente, pouco trabalhadora, ineficiente, incompetente, ameaçadora, depravada, hedonística, etc.” (Mizen, 2002: 5). Só muito raramente a crítica recai sobre a própria organização e funcionamento dos sistemas democráticos, uma tendência que tem vindo a ser paulatinamente invertida, como resultado quer da crise de representação, quer da transformação da condição juvenil.

O actual contexto da democracia portuguesa torna-se particularmente profícuo no que concerne à análise política da juventude. Só muito recentemente assistimos ao surgimento das primeiras gerações integralmente socializadas em democracia, cujas características sociais são, numa diversidade de aspectos, muito diferentes daquelas que conheceram as gerações anteriores - escolaridade, religiosidade, valores sociais, modos de vida, etc. Não é de estranhar, como tal, que a relação que as novas gerações mantêm com o sistema democrático e com as diferentes formas de autoridade evidenciem um conjunto de especificidades. Resta saber até que ponto estas especificidades revelam a presença de uma disfunção (como é típico nas abordagens funcionalistas) ou de uma reacção ao contexto específico que experimentam (mais consentânea com as abordagens geracionais).

Admitimos que os processos de mudança social e política associados à sociedade do risco contribuem para um ressurgimento das teses geracionais, deixadas para segundo plano ante a predominância de explicações centradas na idade, nos ciclos de vida ou num (aparente) contexto de consenso social e político. Como referem Ron Eyerman e Bryan Turner, "ainda que exista literatura sobre a sociologia das gerações, ela é mais implícita do que explícita" (1998: 92), mantendo-se o peso de um conjunto de argumentos que se opõem a uma categorização sociológica da juventude e, logo, à avaliação do seu papel político.

$\mathrm{Na}$ primeira secção do artigo avaliamos o impacto que a própria conceptualização sociológica da juventude tem tido no modo como olhamos o papel político das gerações. Primeiro de tudo, importa saber se, afinal, existe ou não juventude, isto é, se podemos ou não entendê-la como uma categoria sociologicamente pertinente. Como tal, começamos por avaliar 
criticamente dois argumentos contrapostos à categorização sociológica da juventude - a heterogeneidade e a efemeridade da condição juvenil e os respectivos impactos na análise política da juventude. Numa segunda fase, cruzamos um conjunto de argumentos teóricos emergentes da análise da sociedade do risco que, directa ou indirectamente, reforçam alguns dos princípios das teses geracionais e contribuem para um novo olhar sobre o papel da juventude na mudança política.

Dedicamos a última parte do artigo a uma análise empírica, cuja intenção é, fundamentalmente, testar algumas das argumentações teóricas. Para tal, recorremos a uma análise estatística de fontes indirectas (European Values Study de 1999 e European Social Studies de 2004/5), assim como de um inquérito aplicado a 300 jovens (estudantes, desempregados e trabalhadores), desenhado especificamente para responder às principais problemáticas emergentes da discussão teórica (Augusto, 2006). A análise recai essencialmente sobre as formas de mobilização e de participação política, tendo como objectivo avaliar, junto da juventude portuguesa, a validade do modelo teórico apresentado. Propomos, no essencial, uma reflexão crítica e eminentemente teórica, que possa contribuir para uma discussão mais alargada em torno do papel político das gerações, partindo do modo como os jovens experimentam o seu mundo social e político e não apenas das regras prescritivas dos sistemas políticos.

\section{Entre a heterogeneidade e o vácuo social}

A análise da relação entre juventude e política só faz sentido se verificarmos duas condições fundamentais: primeiro, que a juventude constitua, efectivamente, uma categoria sociologicamente relevante; segundo, que essa categoria possa ser parte integrante e activa da mudança política e não apenas um objecto de reprodução das regras do sistema político. Contudo, não tem sido este o discurso dominante e quer a categorização sociológica da juventude, quer o seu papel na mudança política, foram, durante bastante tempo, olhados com alguma desconfiança.

O primeiro obstáculo a uma categorização sociológica da juventude radicou-se no papel central desempenhado pela classe social na modernidade industrial. O título da entrevista de Pierre Bourdieu a Anne-Marie Métailié - “La 'Jeunesse' n'est qu'un mot” (1984: 143) - tornar-se-ia no mote para a chamada corrente classista (Pais, 1993). Indirectamente, Bourdieu retirava força a uma ideia de juventude como categoria analítica ou como espaço de construção de mudança social, resultado dos processos de reprodução social que criavam as "duas juventudes" (1984: 145). Ainda que, como afirma Galland em resposta a Bourdieu, "toda a categoria ope- 
ratória recubra realidades socialmente diversificadas" (2001: 55), a verdade é que, na balança sócio-política da modernidade industrial, a classe continuava a ter um peso significativamente maior do que o da substituição das gerações.

O segundo argumento que se opõe à categorização social da juventude, e que marca ainda muitas abordagens, é a sua efemeridade. A ideia de "assentar na vida" marca uma parte importante do discurso sobre a juventude, entendida como um espaço no ciclo de vida marcado pela inconsciência ou pela irresponsabilidade (temporária, nas palavras de Bourdieu, 1984). A juventude acaba por ser interpretada como uma espécie de "vácuo temporal" no ciclo de vida, que se define mais pelo que não é - nem criança nem adulto - do que pelo que efectivamente é e faz. No fundo, a juventude encontrar-se-ia numa situação de maturação tal que a tornaria, também do ponto de vista político, "able but not allowed" (Baizerman e Magnuson, 1996: 49). Nesta perspectiva, os jovens "nada têm a dizer relativamente às mudanças na sociedade [...] [e] são mais indicadores de estabilidade do que de mudança" (Jowell e Park, 1998: 2), pelo que o seu comportamento político é facilmente assumido como "desviante" ou "patológico", ante a suposta perfectibilidade do sistema.

Como referem Baizerman e Magnuson, "a juventude como estádio retira à juventude as possibilidades do presente, já que a sua 'desadequação' torna a sua realização pessoal e social possível apenas no futuro” (1996: 53). Não se estranha, como tal, que os comportamentos e as atitudes políticas dos jovens sejam frequentemente vistos como algo que "logo passa", sem consequências, e não como uma reacção ao mundo social e político que experimentam. Na maioria dos casos, essa reacção é vista mais como uma patologia associada à condição juvenil do que como um sintoma da (fraca) capacidade por parte do sistema para integrar as novas gerações.

A concepção funcionalista/desenvolvimentista dos ciclos de vida seria reforçada por uma interpretação da juventude centrada na ideia de transição para a vida adulta, que marcaria uma época muito particular do desenvolvimento das sociedades ocidentais - o chamado período da "escola de massas" (Casal, 1997) ou do "Estado keynesiano" (Mizen, 2002) - que os jovens contemporâneos não conheceram (muito menos os portugueses), mas que não deixaria de ter impactos significativos no modo de conceber a sua maior ou menor integração política.

A integração política passaria a depender da estabilidade e sequencialidade que caracterizavam a entrada no mercado de trabalho e a consequente saída de casa dos pais. É por esse motivo que, na maioria das 
democracias ocidentais, se definiram os 18 anos como idade legal para votar, pois correspondiam à idade média de entrada no mercado de trabalho. Um "cidadão pleno" deveria ser, não só mais velho, mas também profissionalmente activo e familiarmente responsável. Teria passado, portanto, a etapa da "irresponsabilidade temporária".

O resultado da crise do Estado keynesiano e da emergência do Estado monetarista seria uma crescente dissonância entre os perfis de juventude traçados pelas instituições reguladoras e as estratégias e trajectórias específicas dos jovens, cada vez mais individualizadas e desestandardizadas. As condições da transição alteraram-se não apenas no que respeita à idade (mais tardia), mas também no que concerne à própria integração socioprofissional (mais instável, incerta e precária). Como refere Mizen, "se ter uma determinada idade era algo relativamente 'bom' frente ao compromisso de inclusão do keynesianismo [...], no monetarismo esta posição de relativa vantagem é invertida" (2002: 16). Crescentemente, verificamos que a especificidade dos contextos experimentados pelos jovens se torna bem mais homogénea do que a suposta etapa que atravessam. Trata-se de uma das condições fundamentais para a emergência de uma actualidade geracional (Mannheim, 1952) que, necessariamente, ocorrerá à margem dos códigos produzidos e institucionalizados pelas gerações anteriores e que os jovens não revêem na sua relação quotidiana com o mundo social e político.

Admitimos que a experimentação destes contextos pode resultar numa crescente incoerência entre os modelos de acção política institucionalizados e as práticas sociais. A individualização e a autonomia das biografias, assim como a perda de importância das instituições e das categorias tradicionais, poderiam contribuir para a afirmação de uma heterodoxia política juvenil que, mais do que representar um apoliticismo, retrataria a relação desinstitucionalizada que as novas gerações mantêm com os domínios políticos, entendendo a política lato sensu e não apenas a sua dimensão convencional.

\section{Juventude, sociedade do risco e desinstitucionalização política: o regresso das gerações?}

As versões mais recentes das teses dos ciclos de vida têm procurado integrar crescentemente a agência e o risco nas suas abordagens, respondendo a uma tendência em que "o poder que as instituições têm para dar sentido às biografias está em declínio [...] [e em que aumentam] as oportunidades de um curso de vida auto-organizado, que $[\ldots]$ acarreta riscos substanciais de falhar e/ou de entrar em conflito com as exigências institucionais" (Heinz 
e Kruger, 2001: 36). É deste conflito que poderão resultar as particularidades políticas dos jovens, uma possibilidade que abriria um extenso debate em torno da condição política da juventude, reavivando muitos dos contributos das teses geracionais e permitindo uma síntese entre correntes teóricas anteriormente tidas como opostas.

Contrariamente ao que acontece nas leituras clássicas dos funcionalistas ou dos desenvolvimentistas, que vêem a transição como adaptação, nas novas tendências de interpretação dos ciclos de vida "os actores individuais e as instituições precisam uns das outras para se adaptarem às reestruturações ou transformações da sociedade" (Heinz e Kruger, 2001: 40). Assim, "ao introduzirmos a agência na equação do curso de vida, temos em conta que as macro-estruturas não determinam o desenho do curso de vida, mas que os indivíduos contribuem para ele, ao serem agentes activos da sua biografia" (ibid.: 41), também do ponto de vista político. Como afirma Heath, os jovens vivem actualmente "um envolvimento com o risco e o reconhecimento de que os caminhos e as direcções do curso de vida tradicional não estarão disponíveis para eles. Assim, os indivíduos vêem-se a si próprios assumindo escolbas biográficas e não tanto aquelas que antes eram consideradas normais" (1999:377-388, sublinhados no original).

A introdução do conceito de individualização na análise da juventude (Furlong e Cartmel, 1997; Nilsen, 1998; Galland, 2001; Heinz e Kruger, 2001; Kelly, 2001; Branner e Nilsen, 2002; Roudet, 2004; Augusto, 2006) teria importantes impactos no modo de analisar a relação entre os jovens e a política, procurando repensar a imagem de apatia e de desinteresse tão frequentemente associada aos primeiros. A pedra-de-toque é colocada na maior ou menor coerência entre os modelos institucionais e o modo desinstitucionalizado e reflexivo como os jovens produzem a sua relação com os domínios públicos e políticos. Para Bernard Roudet, por exemplo, os novos tipos de envolvimento político dos jovens explicam-se em grande parte pelo processo de individualização, que "pode ser sumariamente definido como a vontade de cada indivíduo de escolher as suas maneiras de viver [...], assim como por um declínio do papel das instituições na construção das normas colectivas" (2004: 17).

Assim perspectivadas, as particularidades políticas tão frequentemente associadas aos jovens, como a apatia, o desinteresse ou o fraco envolvimento político poderiam ser interpretadas não tanto como resultado da"irresponsabilidade temporária", mas como um processo biográfico, crescentemente selectivo, e que nem sempre coincide com os modelos institucionalizados. Trata-se, no fundo, de "transformações para além das 
instituições da modernidade" (Giddens, 1992: 116), mas que não são, necessariamente, apolíticas. São, quanto muito, subpolíticas (Beck, 2000).

Como refere Beck, "aquilo que parecia ser uma 'retirada apolítica para a vida privada' [...] na velha interpretação da política, pode representar, quando vista desde outro ângulo, a luta por uma outra dimensão do fenómeno político" (2000: 20). Admitimos que a desinstitucionalização e a privatização possam constituir-se igualmente como indicadores de mudança intergeracional, em resultado do modo como os jovens experimentam os contextos da sociedade do risco e, muito particularmente, do sistema político.

Em certa medida, a geração acaba por surgir como um espaço alternativo ou residual de ancoragem das identidades colectivas ou como um espaço de construção mais autónoma de significados, dada a crise instalada nos modelos ideológicos tradicionais, particularmente depois de 1989 (Eyerman e Turner, 1998; Corsten, 1999; Cavalli, 2004; Lambert, 2004). Mais do que um espaço de transmissão ou de adaptação, a juventude é entendida crescentemente como um espaço de construção e de questionamento dos modelos políticos erigidos pelas gerações anteriores, o que nem sempre resulta numa avaliação positiva da sua intervenção política, em grande medida porque ocorre à margem dos mecanismos institucionais do sistema democrático.

O ressurgimento do conceito de geração na sociologia nas últimas duas décadas deve-se, em grande medida, à intensificação dos efeitos da sociedade do risco, que os jovens experimentam de um modo crescentemente incerto e inseguro. Como referem Eyerman e Turner, "quando muitos sociólogos consideram o declínio ou o fim das classes sociais, pode acontecer que os conflitos geracionais aumentem com o crescimento da incerteza relativamente ao emprego e à segurança" (1998: 98). A nossa proposta é que o aparente alheamento dos jovens relativamente à política "do palácio" reflecte, não um apoliticismo, mas um desencantamento/desconfiança relativamente aos mecanismos formais ou convencionais de integração política, que poderá resultar numa desinstitucionalização da acção política juvenil.

\section{Sinais de desinstitucionalização política e espaços de reclusão}

Defendemos que a análise da relação entre os jovens e a política deve ter em conta a confluência de dois processos - um processo de desinstitucionalização política e um processo de revinculação a domínios não institucionais. Neste sentido, a abstenção, a despartidarização, o desinteresse ou mesmo o não recenseamento poderiam revelar a presença de uma desins- 
titucionalização e não necessariamente de uma despolitização. Paralelamente, as vias não convencionais de participação surgiriam como os espaços de revinculação, como o associativismo, o voluntariado, mas também as acções de confrontação das elites e do poder regulador das instituições.

É sobretudo em situações como a portuguesa, em que os hiatos geracionais são bastante profundos política e socialmente, que o princípio da experiência dos contextos, enunciado por Mannheim (1952), faz mais sentido. Contudo, esta experiência não é necessariamente coerente com as regras institucionais, e é desta potencial incoerência que se alimenta o desencantamento. No fundo, a questão que se impõe quando nos referimos à não integração ou à desinstitucionalização política dos jovens é semelhante à que se coloca Muxel - afinal, "o que é que muda? Os indivíduos ou o próprio contexto político?” (2001a: 37).

Um dos paradoxos frequentemente associado aos jovens é a combinação entre uma defesa acérrima da democracia (particularmente da liberdade de expressão e de associação) e uma rejeição dos modelos de funcionamento do sistema democrático. Segundo Lattes (2001), Henn et al. (2002) ou Kimberlee (2002) é sobretudo da "máquina democrática" que os jovens se afastam e não tanto da democracia, o que uma vez mais revela um processo de individualização e de desinstitucionalização. Ao analisar as representações sociais de democracia produzidas pelos jovens da Europa do Sul, Lattes conclui que "a democracia surge associada a um desejo de liberdade, de autonomia e de respeito pelas diferenças, mais no plano existencial do que no plano político [...], revelando o processo de individualização que caracteriza a experiência da vida em sociedade" (2001: 170). No mesmo sentido, Muxel verifica que os jovens se afastam maioritariamente das querelas partidárias e dos jogos de interesse (1996; 2001a; 2001b; 2001c), enquanto Percheron conclui que "os jovens rejeitam, mais do que os adultos, a mediação das organizações tradicionais, como os partidos políticos ou os sindicatos" (1993: 168). É necessário, como tal, reavaliar a relação que os jovens mantêm com a política e com a democracia, tendo por base o modo como as representam socialmente e não apenas os modelos e os critérios institucionalmente definidos.

Para um número crescente de autores, a acção política dos jovens tem vindo a transitar para domínios não institucionais e a obedecer a novas agendas políticas (nem sempre privilegiadas pelas agendas institucionais). Isto significa, não tanto uma desadaptação política da juventude, mas sobretudo uma reacção ao funcionamento da máquina democrática e uma resposta ao decréscimo de confiança nas elites políticas. Para Muxel, por exemplo, o modo como os jovens se relacionam com a democracia pode, 
inclusive, contribuir para uma "democratização da política" (1996: 12) ou para uma "nova moralidade política" (ibidem), por contraponto à dimensão elitista.

A distinção entre lógicas convencionais e não convencionais de participação política ganhou um espaço significativo na análise política da juventude. As primeiras surgem como os principais espaços de desvinculação, em grande medida porque não respondem às expectativas dos jovens e ao modo como experimentam o seu mundo social e político. As segundas surgem como um potencial espaço de revinculação da participação política, muito particularmente as associações não partidárias e sobretudo aquelas que se organizam em torno de temáticas que, directa ou indirectamente, afectam o seu quotidiano (Galland, 2001; Lattes, 2001; Muxel, 2001c; Benedicto e Moran, 2002; Henn et al., 2002; Augusto, 2006).

A não convencionalidade política dos jovens tem sido associada a três dimensões fundamentais:

a. A dimensão da desinstitucionalização, que resulta num afastamento dos modelos institucionalizados de participação (sobretudo os partidos);

b. A dimensão da relação com as elites, que resulta num abandono do tipo de acção política conduzida por elites (elite driven politics, Watts, 1990), resultante quer da desinstitucionalização, quer do aumento das competências políticas das gerações mais novas;

c. A dimensão da privatização - que resulta numa crescente privatização das lógicas e das agendas de acção política, mais centradas na experiência quotidiana e menos dependentes das agendas e dos modelos institucionalmente propostos.

$\mathrm{Na}$ tentativa de avaliar a presença desta dimensões junto da juventude portuguesa, recorremos à análise de duas fontes indirectas - o European Values Study de 1999 (EVS) e o European Social Studies de 2004/05 e a um inquérito produzido no âmbito da investigação Novos actores sobre velhos palcos - juventude, política e ideologias no Portugal democrático (Augusto, 2006). Este inquérito foi aplicado entre 2004 e 2005 junto de uma amostra de 300 jovens, com idades compreendidas entre os 18 e os 29 anos, seleccionada intencionalmente entre jovens desempregados, estudantes e trabalhadores. ${ }^{1}$

${ }_{1}^{1}$ Para um conhecimento mais aprofundado da metodologia utilizada e dos critérios de selecção da amostra consultar Augusto (2006), no capítulo referente à metodologia. 
Tivemos em conta, neste caso, a mobilização política (tendo por base o interesse pela política), a relação com as instituições políticas (tendo por base a confiança nos políticos e nas instituições) e as formas de participação social e política (combinando vias convencionais e não convencionais de participação). Como veremos, em todos estes itens se detectam importantes sinais de desinstitucionalização e de individualização, que afastam tendencialmente os jovens da "máquina política" e os tornam de algum modo "reclusos" das suas próprias biografias e do seu quotidiano.

\section{Desinteresse ou desconfiança?}

As abordagens mais recentes têm procurado avaliar criticamente a noção de "interesse pela política", não a assumindo como um sintoma automático de apoliticismo, mas como resultado do modo como os jovens definem reflexivamente a "política". Como referem Henn et al., tendo em conta que os jovens tendem a olhar a política "como 'o que acontece no parlamento' e não tanto como 'algo que afecta a minha vida', talvez não seja surpreendente que a juventude tenha uma maior tendência para registar elevados níveis de desinteresse pela política" (2002: 169). Uma das conclusões do estudo coordenado por Muxel e Cacouault junto dos jovens da Europa do Sul confirma particularmente bem esta leitura - cerca de metade dos jovens inquiridos considera que "a política é uma questão que deve ser deixada aos políticos” (2001: 116).

Importa, portanto, não confundir desinteresse pela política com desinteresse pelos mecanismos formais e institucionais da política, em particular os partidos políticos e as elites. Como refere Villaverde Cabral, "as reticências que muitos jovens têm em se identificar com a actual oferta partidária não são de molde a impedi-los de se identificarem genericamente com o sistema democrático" (1998:573). Importa, no fundo, repensar até que ponto serão os jovens a afastar-se da política, ou a máquina política a afastar-se deles.

Em muitos casos, o desinteresse é assumido como uma resposta cínica de desagrado relativamente ao funcionamento do sistema político, em grande medida porque este revela incapacidade para responder aos valores e às expectativas dos jovens (Henn et al., 2002; Kimberlee, 2002; Gauthier, 2003; Augusto, 2006). Noutros casos, responsabiliza-se o contexto vivido pelas novas gerações, marcado pela insegurança e incerteza, que resulta num fraco sentimento de pertença à comunidade. Este facto é evidente quando temos em conta os jovens em situações mais precárias e, muito particularmente, os desempregados (Percheron, 1993; Galland, 2001; 
Muxel e Cacoault, 2001; Augusto, 2006). Também neste caso, não são os jovens, a sua idade ou a sua posição na transição a definir a sua maior ou menor mobilização política, mas um conjunto de características sociopolíticas que marcam o contexto que experimentam e que, em grande medida, escapam ao seu controlo.

Tornou-se comum afirmar que os jovens têm um menor interesse pela política, o que contribuiria para alimentar uma imagem de apoliticismo e de fraca mobilização política. No caso português, e tendo em conta os dados nacionais extraídos do European Values Study de 1999 (ESS) e do European Social Studies de 2004/05 (ESS), não verificamos essa tendência. Contrariamente ao que é comummente referido, os dados nacionais revelam uma grande proximidade entre o nível de interesse revelado pelas gerações mais velhas e pelas gerações mais novas, pondo em causa a centralidade do critério etário e, por conseguinte, os argumentos centrados na "irresponsabilidade temporária".

QUADRO 1 - Comparação intergeracional do interesse pela política

\begin{tabular}{|c|c|c|}
\hline & $\begin{array}{c}\text { Média de interesse } \\
\text { EVS 1999 (Portugal) } \\
\text { (escala 1-4; } \mathrm{n}=997)\end{array}$ & $\begin{array}{c}\text { Média de interesse } \\
\text { ESS 2004 (Portugal) } \\
\text { (escala 1-4; } \mathrm{n}=1997)\end{array}$ \\
\hline $18-29$ & 2,13 & 2,01 \\
\hline $30-40$ & 2,15 & 2,12 \\
\hline $41-50$ & 2,07 & 1,96 \\
\hline $51-60$ & 2,13 & 2,12 \\
\hline $61-70$ & 1,93 & 1,94 \\
\hline $71-80$ & 1,75 & 1,81 \\
\hline $81 \mathrm{e}+$ & 1,82 & 1,68 \\
\hline
\end{tabular}

Ante os dados, não podemos afirmar que exista um menor interesse por parte das gerações mais novas (considerando neste caso os jovens eleitores), o que no fundo não é de estranhar e acaba por reforçar não só um dos princípios fundamentais da teoria geracional - a experimentação dos contextos - mas também a importância da ampliação dos recursos, particularmente da escolaridade. Como podemos verificar, a generalidade dos grupos etários aproxima-se do valor 2, isto é, do "pouco interesse", não existindo uma relação directa entre o interesse revelado pela política e a idade dos inquiridos. Os jovens entre os 18 e os 29 anos estão, inclusivamente, entre os mais interessados, sobretudo quando comparados com as gerações mais velhas (mais de 61 anos). 
Obviamente, existem factores contextuais que marcam a socialização política de cada um destes grupos etários, com especial destaque para as coortes mais velhas, cuja juventude foi vivida em contextos pré-democráticos, nada férteis em discussão política. Parece-nos, portanto, que os dados nos evidenciam mais a presença de efeitos geracionais, resultado do contexto em que cada coorte viveu a sua juventude, do que de efeitos de idade ou de ciclo de vida, tão frequentemente utilizados para explicar o desinteresse político juvenil. Inclusivamente, quando restringimos a análise aos jovens (entre os 18 e os 29 anos), não verificamos a presença destes efeitos. Do mesmo modo, não registamos a presença de efeitos de transição, não existindo nenhuma relação significativa entre as posições na transição (pública e privada) e o maior ou menor interesse pela política, o mesmo acontecendo quando consideramos a classe social de origem.

Os dados de ambos os inquéritos contradizem a imagem que comummente se produz da "moratória política", mas revelam igualmente a presença de um paradoxo. Na verdade, tudo apontaria para uma ampliação do interesse pela política, tendo em conta que o capital escolar das gerações mais novas é significativamente maior e que a escolaridade é a variável que mais condiciona o interesse pela política $(r=0,277 * *$ no caso do EVS e $r=0,291 * *$, no caso do ESS). Significa, portanto, que a ampliação das competências sociais e políticas dos jovens contribuiu, quanto muito, para uma manutenção intergeracional de um fraco interesse pela política, ainda que neste caso não a possamos associar à escassez de competências sociopolíticas e democráticas, como acontece junto das gerações mais velhas.

Uma das explicações para o paradoxo entre um aumento do capital escolar e uma manutenção dos níveis de interesse pela política podemos encontrá-la na igual manutenção intergeracional de uma fraca confiança nos partidos e nas elites políticas. Neste caso, no entanto, nem mesmo a característica que melhor distingue pais de filhos - a escolaridade revela uma relação significativa. Na verdade, e tal como verificou Villaverde Cabral (2004) junto da população portuguesa, a (fraca) confiança nos políticos atravessa indiferenciadamente as características sociais dos jovens. Independentemente da classe social, do sexo, da escolaridade, da idade ou da posição na transição, os jovens portugueses (assim como a generalidade das coortes) revelam uma fraca confiança nas instituições políticas, muito particularmente nos partidos políticos e nos respectivos líderes.

Admitindo que os jovens tendem a recusar não tanto a democracia, mas sobretudo a mediação dos partidos políticos e das elites que os lideram, seria de esperar que os níveis de confiança variassem significativa- 
mente quando comparada a confiança no parlamento, nos partidos e nos líderes. O inquérito do ESS possibilita essa avaliação, tendo em conta que contempla, separadamente, estes três tipos de confiança. Quando analisamos os níveis médios de confiança (numa escala 0-10), verificamos que "os políticos" são os que inspiram menor confiança junto dos jovens $(2,97), \operatorname{logo}$ seguidos dos partidos $(3,13)$. Apenas a "casa da democracia" regista um valor médio de confiança $(4,75)$, que se afasta claramente dos valores anteriores.

Também neste caso se verifica uma grande proximidade entre as diferentes coortes, pelo que não podemos afirmar que os jovens são mais ou menos confiantes do que as gerações mais velhas. Aquilo que podemos dizer é que a desconfiança decresce à medida que nos deslocamos para os instrumentos tradicionais de mediação política, reflectindo duas das dimensões consideradas anteriormente - o afastamento da elite driven politics (Watts, 1990) e da política partidária.

Este afastamento pode, em grande medida, explicar o paradoxo entre o aumento da escolaridade e a manutenção dos níveis de interesse pela política. Segundo os teóricos da mudança de valores, que têm por base as propostas de Ronald Inglehart (1977, 1990, 1997), o aumento das competências políticas (possibilitado pelo aumento do capital escolar), assim como o aumento da segurança física (ausência de guerras ou conflitos que ponham em causa essa segurança) torna os jovens menos dependentes dos impulsos políticos provenientes das elites e das instituições e, logo, mais autónomos no modo como desenham a sua experiência política. Mais do que favorecer o acompanhamento de uma lógica convencional da política, a escolaridade pode, como tal, contribuir para uma confrontação dessa lógica, resultado da ampliação da capacidade crítica e dos níveis de mobilização cognitiva.

Como seria de esperar, o interesse pela política varia em função da confiança depositada quer nas instituições políticas, quer nas elites, o que confirma em grande medida a desinstitucionalização e o afastamento da política conduzida por elites. O interesse pela política varia claramente em função do grau de confiança que os jovens depositam no parlamento $\left(\mathrm{r}=0,211^{* *}\right)$, nos partidos $\left(0,284^{* *}\right)$ ou nos políticos $\left(0,233^{* *}\right)$. Como podemos verificar, ainda que todas as variáveis revelem níveis de correlação significativos, é a confiança nos partidos que revela uma correlação mais expressiva. Na tentativa de avaliar o papel que cada tipo de confiança desempenha nos níveis de interesse, produzimos uma regressão múltipla, que acaba por evidenciar o papel desempenhado pela (fraca) confiança nos partidos políticos. 
QUADRO 2 - Regressão múltipla - interesse pela política e confiança no parlamento, nos partidos e nos políticos

\begin{tabular}{|l|c|c|c|}
\hline & Beta & $\mathrm{t}^{*}$ & Sign. \\
\hline Confiança nos políticos &,- 069 &,- 711 &, 477 \\
\hline Confiança no parlamento &, 101 & 1,752 &, 081 \\
\hline Confiança nos partidos &, 303 & 3,096 &, 002 \\
\hline
\end{tabular}

* Considera-se que a relação é significativa quando $t \geq 2,0$ ou $t \leq-2,0$. Variável dependente: Interesse pela política. Variância explicada do modelo $=0,306$.

Como podemos verificar, a única variável que apresenta valores significativos é a confiança nos partidos políticos. À semelhança do que nos é revelado por um número crescente de estudos, verificamos que a fraca confiança nos partidos políticos marca, pela negativa, o grau de mobilização política dos jovens. Admitimos, tal como Muxel, que esta desconfiança possa ser alimentada pela fragilidade das querelas partidárias e pela redução do jogo político às "divisões internas, às alianças e aos oportunismos" (1996: 10), em detrimento dos projectos e dos conteúdos. Esta limitação da política e da democracia aos mecanismos formais e respectivos códigos acaba por ter uma dupla consequência: por um lado afasta a juventude desses mesmos mecanismos, favorecendo a sua definição pela negativa, por outro, contribui para uma representação da política como um "domínio das pessoas sem escrúpulos e do dinheiro" (Muxel, 1996: 10, citando uma jovem entrevistada).

É da política partidária que os jovens tendencialmente se afastam e isso reflecte-se particularmente bem na relação entre (des)interesse e (des)confiança. No entanto, não é apenas esta relação que revela este afastamento. Como adiante veremos, a relação que os jovens mantêm com as instituições políticas, em particular com os partidos, é pouco intensa, sobretudo quando comparada com outras formas de mobilização, com um especial destaque para o associativismo.

\section{Participação política - do convencional ao não partidário}

A conclusão emergente da maioria dos trabalhos aponta para uma crescente desinstitucionalização da participação política dos jovens e a sua concentração em torno, quer de novas formas de acção colectiva, quer de novas agendas temáticas. As associações voluntárias, as associações ligadas ao lazer (desportivas, recreativas ou culturais) transformaram-se nos principais espaços de participação dos jovens, retirando centralidade às lógicas institucio- 
nalmente definidas e reforçando a importância dos domínios privados e do quotidiano juvenil. Como refere Muxel, "outras formas de ocupar o terreno de expressão democrática podem emergir, pela acção colectiva, por um reposicionamento dos actores sociais e políticos, ou ainda por uma deslocação do terreno partidário para o terreno associativo" (2001c: 217-218).

Quando avaliamos o tipo de instrumentos de mediação da acção pública e política privilegiados pelos jovens, verificamos uma situação em tudo idêntica - as vias partidária e institucional são as mais preteridas. No inquérito aplicado à nossa amostra, procurámos conhecer os principais mecanismos de intervenção política privilegiados pelos jovens. Neste sentido, pedimos-lhes que, num conjunto de instrumentos de participação política, referissem quais os que já utilizaram, os que admitem utilizar e aqueles que jamais utilizariam.

Pretendemos avaliar em que medida os jovens revelam um afastamento da política dirigida pelas elites e a procura de novos espaços de acção política, pelo que contemplámos formas convencionais e não convencionais de participação política. Entre as formas convencionais (conduzidas por elites) destacámos a participação em actividades partidárias ou a comunicação com as instituições políticas (quer directamente, quer através da comunicação social); entre as formas não convencionais (de confrontação das elites), destacámos a assinatura de petições, a participação em manifestações, o boicote a produtos por motivos políticos ou ambientais e a participação electrónica (online).

QUADRO 3 - Modalidades de participação política

\begin{tabular}{|c|c|c|c|}
\hline & Já fez & Admite fazer & Não faria \\
\hline $\begin{array}{c}\text { Assinar uma petição ou um abaixo-assinado } \\
(\mathrm{n}=291)\end{array}$ & $60,8 \%$ & $30,2 \%$ & $8,9 \%$ \\
\hline Participar numa manifestação ( $\mathrm{n}=274)$ & $55,8 \%$ & $34,4 \%$ & $9,9 \%$ \\
\hline $\begin{array}{c}\text { Fazer um boicote a produtos por motivos } \\
\text { ambientais ou políticos ( } \mathrm{n}=287)\end{array}$ & $14,3 \%$ & $64,8 \%$ & $20,9 \%$ \\
\hline $\begin{array}{c}\text { Participar em actividades de partidos políticos } \\
\text { (comícios, campanhas, etc.) ( } \mathrm{n}=292)\end{array}$ & $19,2 \%$ & $43,2 \%$ & 37,7 \\
\hline $\begin{array}{c}\text { Contactar instituições políticas ou a comunica- } \\
\text { ção social para dar as suas opiniões ( } \mathrm{n}=292)\end{array}$ & $7,9 \%$ & $64 \%$ & $28,1 \%$ \\
\hline $\begin{array}{c}\text { Participar em fóruns ou chats de discussão polí- } \\
\text { tica na internet ( } \mathrm{n}=294)\end{array}$ & $10,2 \%$ & $50,3 \%$ & $37,4 \%$ \\
\hline
\end{tabular}


Como podemos verificar (e à semelhança do que revelam os dados nacionais do EVS 1999), a assinatura de petições, assim como a participação em manifestações são as modalidades de participação mais frequentes, tendo já sido utilizadas por mais de metade dos inquiridos $(60,8 \%$ e $55,8 \%$, respectivamente). Confirmando de algum modo as nossas expectativas, verificamos que as formas convencionais de participação, como o contacto com instituições políticas ou a participação nas actividades dos partidos são não só menos frequentes, mas também mais rejeitadas pelos jovens. Somente 7,9\% dos inquiridos contactou instituições políticas ou a comunicação social para dar a sua opinião e apenas 19,2\% participou em actividades de partidos políticos (campanhas, comícios, etc.). Por outro lado, verificamos que a actividade partidária é a modalidade de participação mais rejeitada $-37,7 \%$ dos inquiridos refere que nunca participou em actividades partidárias e que não pretende fazê-lo no futuro.

A participação em lógicas não convencionais aumenta à medida que subimos na escolaridade dos inquiridos, algo que não acontece quando avaliamos a relação com os partidos ou com as instituições políticas. Verificamos, também neste caso, que a maior mobilização cognitiva, assim como a ampliação das competências políticas que lhe está associada, contribuem para uma maior procura de formas mais autónomas de participação, à margem dos domínios partidários. O recurso a petições confirma particularmente bem esta tendência $-20 \%$ dos inquiridos com o ensino preparatório já utilizaram este recurso de participação, sendo este valor de $47,7 \%$ entre os jovens com o $9^{\circ}$ ano; $58,2 \%$ entre os que completaram o ensino secundário; $79 \%$ entre os estudantes universitários e $80 \%$ entre os indivíduos com o ensino superior. $\mathrm{O}$ mesmo acontece em relação às manifestações, aos boicotes e, em menor grau, à participação electrónica.

\subsection{O Associativismo como espaço de revinculação política?}

Uma outra questão que procurámos avaliar foi o recurso aos diferentes tipos de associações ou organizações e, também neste caso, verificámos um afastamento das organizações convencionais, como os partidos políticos ou os sindicatos. À semelhança do que concluem a maioria dos estudos (Ferreira, 1993; Percheron, 1993; Muxel, 1996, 2001a, 2002; Benedicto e Morán, 2002, 2003; Kimberlee, 2002; Gauthier, 2003, Ferreira e Silva, 2005), verificamos que os jovens procuram essencialmente organizações não partidárias para exercitar a sua participação cívica.

Questionámos os jovens relativamente à sua participação em diferentes tipos de associações ou organizações, desde as associações recreativas, culturais ou desportivas até aos sindicatos ou aos partidos políticos. 
Pretendíamos saber quantos já participaram em cada uma das formas de associação, quantos ainda o fazem e quantos nunca o fizeram. A maioria dos inquiridos $(59,4 \%)$ já participou em actividades de associações, mas este valor reflecte fundamentalmente a participação em associações não partidárias e não sindicais, como podemos verificar pela análise do quadro 4 (percentagens em linha):

QUADRO 4 - Mecanismos colectivos de participação

\begin{tabular}{|l|c|c|c|}
\hline \multicolumn{1}{|c|}{$\mathrm{N}=177$} & $\begin{array}{c}\text { Nunca } \\
\text { participou }\end{array}$ & $\begin{array}{c}\text { Já } \\
\text { participou }\end{array}$ & $\begin{array}{c}\text { Ainda } \\
\text { Participa }\end{array}$ \\
\hline Associação ou grupo desportivo & $21,9 \%$ & $60,7 \%$ & $17,4 \%$ \\
\hline $\begin{array}{c}\text { Grupo cultural ou recreativo (música, teatro, } \\
\text { cinema, etc.) }\end{array}$ & $47,8 \%$ & $44,9 \%$ & $7,3 \%$ \\
\hline Grupo religioso & $53,7 \%$ & $39,5 \%$ & $6,8 \%$ \\
\hline Associação de estudantes & $46 \%$ & $49,4 \%$ & $4,5 \%$ \\
\hline Sindicato ou associação profissional & $86,4 \%$ & $6,3 \%$ & $7,4 \%$ \\
\hline Partido político & $80,2 \%$ & $10,7 \%$ & $9 \%$ \\
\hline $\begin{array}{c}\text { Associação cívica (ambientalista, feminista, asso- } \\
\text { ciação de consumidores, de moradores, etc.) }\end{array}$ & $88,6 \%$ & $7,4 \%$ & $4 \%$ \\
\hline
\end{tabular}

Os partidos políticos, os sindicatos (mesmo entre os jovens trabalhadores) e as associações cívicas são os espaços de intervenção pública menos privilegiados pelos jovens. São sobretudo as associações associadas ao lazer - desportivas, recreativas ou culturais - assim como as que estão mais directamente associadas às suas experiências particulares (associação de estudantes) que mais atraem os jovens. As associações tradicionalmente assumidas como "políticas", quer as institucionais (como os partidos políticos e os sindicatos), quer as não institucionais (como as associações cívicas) são aquelas que registaram os menores níveis de participação. Na verdade, $78,1 \%$ dos inquiridos que participam em actividades associativas fê-lo em associações desportivas e 52,2\% em associações recreativas ou culturais, valores bastante distantes daqueles que registámos em relação aos partidos políticos, onde já participaram 19,7\% dos inquiridos e onde apenas $9 \%$ participam actualmente.

Se tivermos em conta apenas o tipo de associações em que os inquiridos participam ou já participaram, verificamos que são as associações ligadas ao quotidiano juvenil que mais cativam os jovens e não tanto as 
formas convencionais de participação. A única excepção serão, possivelmente, as associações de estudantes que funcionam, em muitos casos, como trampolins políticos ou como "escolas" da política e que, como tal, poderão surgir na fronteira entre o convencional e o não convencional.

Uma avaliação completa do associativismo juvenil somente é possível através de uma avaliação do próprio funcionamento das associações, algo que este estudo não contempla. É importante, em primeiro lugar, avaliar a relação que estas mantêm com as formas convencionais de participação, muito particularmente com os partidos e com as respectivas elites. Tendo em conta que os jovens rejeitam maioritariamente as formas partidárias de participação ou a política conduzida por elites (actuais ou futuras), é de esperar que a colonização partidária e elitista das associações tenha um efeito de repulsa junto dos jovens.

Em certa medida, podemos dizer que os jovens se recusam a contribuir para lógicas partidárias e para trajectórias pessoais de liderança, como resultado da ampliação das suas próprias competências políticas e de uma fraca confiança nos partidos e nas elites. Tal como Castillo, admitimos que "existe uma crise das formas convencionais de participação, ou das 'formas de participação conduzidas pelas elites' [...] [como reacção] contra a burocracia partidária e outras formas oligárquicas de participação política” (2003: 2-3).

Â luz da individualização e da desinstitucionalização que caracteriza os jovens contemporâneos, o associativismo surge claramente como uma alternativa ou como um espaço de revinculação da acção colectiva, uma possibilidade que é tanto mais válida quanto mais se aproximar do seu quotidiano e menos depender de (ou contribuir para) lógicas partidárias. Admitimos, contudo, que a reclusão junto de modelos de associativismo ligados ao quotidiano, ao lazer ou à vida privada pode representar uma resposta individualizada à perda de centralidade ou de capacidade de atracção das instituições e dos modelos institucionalizados de ancoragem política.

\section{Considerações finais}

A análise da relação entre juventude e política tem vindo a ser objecto de uma profunda revisão nos últimos anos, como resultado de transformações profundas nas lógicas de representação política, na condição juvenil e nos contextos experimentados pelas novas gerações. A maioria dos estudos revela um afastamento da "doxa dominante" (Pais, 1990), que assume a juventude como problemática ou desadaptada, revelando uma maior preocupação com a avaliação dos motivos dessa "desadaptação". Mais do que pressupor uma 
suposta perfectibilidade do sistema político e uma consequente "desadaptação" política da juventude, a maioria das interpretações teóricas mais recentes concebe esta relação numa lógica de mútua influência.

Os contextos da sociedade do risco, experimentados na fase formativa, são substancialmente diferentes daqueles que conheceram os seus pais e, neste aspecto, a sociedade portuguesa é bastante fértil em exemplos. A crescente precarização da integração socioprofissional, o aumento do capital escolar, a secularização, o casamento "tardio", a orientação para os valores ou mesmo a esquerdização são apenas alguns dos exemplos que nos aproximam da realidade conhecida na maioria das sociedades ocidentais (Augusto, 2006). Existem, no entanto, outras particularidades geracionais, que nos afastam da realidade experimentada noutros contextos. Basta pensarmos que ainda há bem pouco tempo conhecemos as primeiras gerações "filhas da democracia".

O critério da socialização para o apoliticismo, que se poderia utilizar para justificar a apatia, o desinteresse ou a desinformação das gerações pré-25 de Abril, não se aplica junto destas gerações. Do mesmo modo, elas não acompanharam o processo de institucionalização política, como a "geração do 25 de Abril".

Este conjunto de particularidades reforça os princípios das teses geracionais, mas revela também um conjunto de características, que poderíamos assumir como potenciadoras da mobilização política dos jovens, em particular a escolaridade e a socialização democrática. No entanto, a juventude portuguesa continua a revelar baixos níveis de mobilização política. O interesse pela política mantém-se em níveis baixos, próximos aos das gerações dos seus pais, tal como acontece com a confiança nas instituições políticas e nas elites que as lideram, o que em grande medida explica o paradoxo entre o aumento dos recursos sociais e políticos e a manutenção dos níveis de mobilização.

Tornou-se comum afirmar que os jovens se afastam crescentemente da política, mas nem sempre nos perguntamos de que política se afastam. $\mathrm{Na}$ verdade, a relação entre as lógicas institucionais de funcionamento do sistema democrático e a experimentação dos contextos vividos pelos jovens revela frequentemente dissonâncias. Admitimos que estas dissonâncias são consequência, não de um "natural" apoliticismo juvenil, resultante da idade ou da fase de adaptação que atravessam, mas sobretudo da combinação de dois processos paralelos e contraditórios - um processo de estandardização e institucionalização dos modelos de relação com o sistema político e um processo de desinstitucionalização e de individualização dos modos de acção política privilegiados pelos 
jovens. É certo que, em última instância, a afirmação deste último processo se deve a um conjunto de particularidades sociais e políticas dos jovens. No entanto, tais características são transversais à própria condição juvenil e resultam quer dos contextos experimentados, quer da ampliação dos recursos, em particular do capital escolar, que contribuem para a afirmação de importantes traços geracionais.

Um destes traços geracionais é, claramente, a desinstitucionalização das práticas políticas dos jovens e, muito em particular, o seu afastamento das lógicas partidárias e conduzidas por elites. Trata-se de uma das características associada à sociedade do risco, aos processos de individualização e a uma crescente autonomização das práticas políticas, que se transferem tendencialmente para domínios não convencionais. Dois dos factores que mais contribuem para esta desinstitucionalização e autonomização são, no fundo, as características que melhor distingue as gerações anteriores das actuais - a escolaridade e a socialização democrática, esta última muito marcada por valores centrados na liberdade de expressão e de associação.

Em certa medida, podemos falar de uma deslocação do terreno partidário para o terreno associativo, como verifica Muxel (1996; 2001c). No entanto, estes espaços de revinculação acabam por revelar uma outra dimensão da relação entre jovens e política - a valorização da esfera privada e do quotidiano. O tipo de associativismo privilegiado pelos jovens (desportivo, cultural ou recreativo) revela particularmente bem esta tendência. Trata-se de uma estratégia de reclusão nos domínios privados que, admitimos, possa revelar uma espécie de resposta cínica (e privada) à continuada incapacidade dos instrumentos institucionais para gerar interesse, confiança e, logo, mobilização política. Como diz Beck, é o "lado de fora virado para dentro e tornado privado" (1998: 133, sublinhado no original) e as instituições políticas são parte importante deste processo.

\section{Referências bibliográficas}

Augusto, Nuno Miguel (2006), Novos actores sobre velhos palcos: juventude, política e ideologias no Portugal democrático. Covilhã: Universidade da Beira Interior (tese de doutoramento).

Baizerman, Michael; Magnuson, Doug (1996), "Do We Still Need Youth as a Social Stage?”, Young, 4(3), 48-60.

Beck, Ulrich (2000), "A reinvenção da política", in Ulrich Beck; Anthony Giddens; Scott Lash, Modernização Reflexiva: Política, tradição e estética no mundo moderno. Oeiras: Celta, 1-51. 
Beck, Ulrich (1998), Risk Society. London: Sage.

Benedicto, Jorge; Morán, M. Luz (2002), La construcción de una ciudadania activa entre los jóvenes. Madrid: Instituto de la Juventud.

Benedicto, Jorge; Morán, M. Luz (2003), Aprendiendo a ser ciudadanos: experiencias sociales y construcción de la ciudadanía entre los jóvenes. Madrid: Instituto de la Juventud.

Bourdieu, Pierre (1984), Questions de sociologie. Paris: Minuit.

Branner, Julia; Nilsen, Ann (2002), "Young People's Time Perspectives: From Youth to Adulthood", Sociology, 36(3), 513-537.

Cabral, Manuel Villaverde (1998), “Atitudes políticas e simpatias partidárias dos jovens portugueses”, in M. Villaverde Cabral; José Machado Pais (orgs.), Jovens portugueses de hoje. Oeiras: Celta, 359-382.

Cabral, M. Villaverde (2004), "Confiança, mobilização e representação política em Portugal”, in A. Freire; M. C. Lobo; P. Magalhães (orgs.), Portugal a votos: as eleições legislativas de 2002. Lisboa: ICS, 301-332.

Casal, Joaquim (1997), "Modos emergentes de transición a la vida adulta en el umbral del siglo XXI: aproximación sucesiva, precaridad y desestruturación”, in José Machado Pais; Lynne Chrisholm (orgs.), Jovens em mudança. Lisboa: ICS, 121-141.

Castillo, A. Jaime (2003), "Political Culture and Representative Democratic Institutions in Spain”. Múrcia: VI Conferência da ESA.

Cavalli, Alessandro (2004), "Generations and Values Orientations" Social Compass, 51(2), 155-168.

Comissão das Comunidades Europeias (2001), Livre Blanc de la Commission Européenne: un nouvel élan pour la jeunesse européenne. Bruxelles.

Corsten, Michael (1999), "The Time of Generations", Time and Society, 8(2), 249-272.

Eyerman, Ron; Turner, Bryan C. (1998), “Outline of a Theory of Generations”, European Journal of Social Theory, 1(1), 91-106.

Ferreira, Paulo Antunes (1993), Valores dos jovens portugueses nos anos 80. Lisboa: ICS/Instituto da Juventude.

Ferreira, P. Moura; Silva, P. Alcântara (2005), O associativismo juvenil e a cidadania política. Lisboa: ICS.

Furlong, Andy; Cartmel, Fred (1997), "Risk and Uncertainty in the Youth Transition", Young, 5(1), 1-17.

Galland, Olivier (2001), Sociologie de la jeunesse. Paris: Armand Colin.

Gauthier, Madeleine (2003), "The Inadequacy of Concepts: The Rise of Youth Interest in Civic Participation in Quebec", Journal of Youth Studies, 6(3), 265-276.

Giddens, Anthony (1992), As consequências da modernidade. Oeiras: Celta.

Heath, Shirley B. (1999), "Rethinking Youth Transitions", Human Development, 42, 376-382. 
Heinz, Walter R.; Kruger, Helga (2001), "Life Course: Innovations and Challenges for Social Research", Current Sociology, 49(2), 29-45.

Henn, Matt et al. (2002), "A Generation Apart? Youth and Political Participation in Britain”, Journal of Politics and International Relations, 4, 167-192.

Inglehart, Ronald (1977), The Silent Revolution. New York: Princeton UP.

Inglehart, Ronald (1990), Culture Shift in Advanced Industrial Society. New Jersey: Princeton UP.

Inglehart, Ronald (1997), Modernization and Post-modernization: Cultural, Economic and Political Change in 43 Societies. New Jersey: Princeton UP.

Jowell, Roger; Park, Alison (1998), "Young People, Politics and Citizenship: A Disengaged Generation?”, Colloquium on the Values, Attitudes and Bebaviour of Young People in the 1990s. London: Citizenship Foundation, 1-18.

Kelly, Peter (2001), "Youth at Risk: Processes of Individualisation and Responsabilisation in the Risk Society", Discourse: Studies in the Cultural Politics of Education, 22(1), 23-33.

Kimberlee, Richard H. (2002), "Why Don't British Young People Vote at General Elections?", Journal of Youth Studies, 5(1), 85-98.

Lambert, Yves (2004), "De la classe sociale à la génération comme facteur principal de differentiation des attitudes religieuses”, Social Compass, 51(2), 249-254.

Lattes, Gianfranco B. (2001), "La démocratie au miroir de la jeunesse", in A. Muxel; M. Cacouault, Les jeunes de l'Europe du Sud et la politique, une enquête comparative: France, Italie, Espagne. Paris: L'Harmattan, 167-188.

Mannheim, Karl (1952), Essays on the Sociology of Knowledge. Oxford: Oxford UP. Mizen, Phillip (2002), "Putting the Politics Back into Youth Studies: Keynesianism, Monetarism and the Changing State of Youth", Journal of Youth Studies, 5(1), 5-20.

Muxel, Anne (1996), “Les jeunes français en attente de politique?”, Working Paper-Centre d'Étude de la Vie Politique Française, 123, 1-21.

Muxel, Anne (2001a), L'expérience politique des jeunes. Paris: Presses de Sciences Politiques.

Muxel, Anne (2001b), "La Perception de l'univers politique”, in A. Muxel; M. Cacouault, Les jeunes de l'Europe du Sud et la politique, une enquête comparative: France, Italie, Espagne. Paris: L'Harmattan, 101-132.

Muxel, Anne (2001c), "La participation politique hors du jeu et dans le jeu démocratique”, in A. Muxel; M. Cacouault, Les jeunes de l'Europe du Sud et la politique, une enquête comparative: France, Italie, Espagne. Paris: L'Harmattan, 217-256.

Muxel, Anne (2002), "La Participation politique des jeunes: soubresauts, fractures et ajustements", Revue Française de Science Politique, 52, 5-6.

Muxel, Anne; Cacouault, M. (2001), Les jeunes de l'Europe du Sud el la politique: une enquête comparative France, Italie, Espagne. Paris: L'Harmattan. 
Nilsen, Ann (1998), "Jovens para sempre? Uma perspectiva da individualização centrada nos trajectos de vida”, Sociologia. Problemas e Práticas, 27, 59-78.

Pais, José Machado (1990), “A construção sociológica da juventude”, Análise Social, 105-106, 139-165.

Pais, José Machado (1993), Culturas juvenis. Lisboa: INCM.

Percheron, Annick (1993), Socialisation politique. Paris: Armand Colin.

Roudet, Bernard (2004), "Entre responsabilisation et individualisation: les évolutions de l'engagement associatif”, Lien Social et Politiques, 51, 17-27.

Watts, Meredith (1990), "Orientation Towards Conventional and Unconventional Participation among West German Youth”, Comparative Political Studies, 23(3), 283-313. 